\title{
The Role of Myelogram in Diagnosis of Malignant Hemopathies
}

\author{
Skali Hajar ${ }^{*}$, Lazrak Fatima Zahrae, Yahyaoui Hicham, Ait Ameur Mustapha, Chakour Mohamed \\ Hematology Laboratory Military Hospital Avicenna of Marrakech, Faculty of Medicine and Pharmacy of Marrakech, University of Cadi Ayyad \\ of Marrakech, Marrakech, Morocco
}

Email address:

hajarskali91@gmail.com (S. Hajar)

${ }^{*}$ Corresponding author

\section{To cite this article:}

Skali Hajar, Lazrak Fatima Zahrae, Yahyaoui Hicham, Ait Ameur Mustapha, Chakour Mohamed. The Role of Myelogram in Diagnosis of Malignant Hemopathies. American Journal of Laboratory Medicine. Vol. 6, No. 5, 2021, pp. 70-76. doi: 10.11648/j.ajlm.20210605.11

Received: September 18, 2021; Accepted: October 5, 2021; Published: October 12, 2021

\begin{abstract}
The myelogram is an essential investigation for the diagnosis and management of malignant hemopathies. The final interpretation requires the integration of peripheral blood count and smear, with the results of supplementary tests such as immunophenotyping, cytogenetic analysis and molecular genetic studies as appropriate, in the context of clinical and other diagnostic findings. This retrospective study conducted at the Hematology Laboratory of the Military hospital Avicenna in Marrakech over a period of two years, from January 2018 to December 2019, aimed to evaluate the practice and the contribution of the myelogram in diagnosis in patients in the Hematology Laboratory and to report the epidemiological profile of malignant hemopathies diagnosed in our Laboratory. In our study, out of 420 myelograms received in the Hematology Laboratory of the military hospital in Marrakech, 70 cases (17\%) of malignant hemopathies were collected. The predominant age range was 61 to 70 years old. The male gender was predominant $(64 \%)$ with a sex-ratio at 1,8 . The clinical indications of myelogram were dominated by anemic syndrome, tumoral syndrome. Biologically, the Peripheral Blood count and smear abnormalities were the most frequent. Acute leukemias were accounted for 35\% of all malignant pathologies diagnosed in our laboratory of which $79 \%$ myeloid, 21\% lymphoid. Multiple myelomas were found in 33\%, myelodysplastic syndromes in $17 \%$ and Chronic myeloid leukemia in $9 \%$. The role of the myelogram in diagnostic of malignant hemopathies is based on its good interpretation which is directly linked to the rigor of its realization.
\end{abstract}

Keywords: Myelogram, Bone Marrow Smear, Blood Smear, Malignant Hemopathy, Leukemia

\section{Introduction}

The myelogram is mainly performed for cytomorphological examination of bone marrow cells, but also to proceed to other analyses such as immunophenotypic, flow cytometry, cytogenetic, molecular genetic, and microbiological tests. It is an important medical procedure for the diagnosis, staging, and follow-up of patients with hematological diseases and for investigating various non-hematological conditions including storage diseases, inborn errors of metabolism, metastatic cancer, and infection that has spread to the bone marrow. The indications for myelogram are established in routine hematology practice. The success of the bone marrow (BM) smear depends first of all on the pre-analytical phase: the quality of the sample and that of the smears (correctly made and well stained). A comprehensive diagnosis of a BM disorder often requires an experienced cytologist to do the integration of various diagnostic approaches. These include peripheral blood (PB) counts and smear evaluation, BM aspirate smear, particle clot section, BM trephine biopsy and imprint morphology, together with results of other relevant investigations such as cytochemistry, immunophenotypic analysis, cytogenetic and molecular genetic techniques, as well as biochemical and microbiological test results, as appropriate. The final interpretation should be in the context of clinical and preliminary diagnostic findings. Current methods for the preparation, processing and reporting of $\mathrm{BM}$ specimens can be highly variable. The lack of uniformity can lead to inconsistencies in disease diagnosis and classification, and thereby affect treatment and clinical outcomes. Malignant 
hemopathies are all neoplasms developed at the expense of hematopoietic tissue and lymph nodes. It covers a broad range of diseases with variable presentations. They result from proliferation of mature or immature blood cells, and they often have a pejorative prognosis. Most malignant hemopathies have no identified etiology. They are the result of mutations that occur in a cell clone, following damage to DNA during its duplication during mitosis. It is usually a series of successive mutations which seem to confer full malignancy on the clone concerned [1-10]. The purpose of this work was to evaluate the practice and the role of the myelogram in diagnosis in patients in the Hematology Laboratory of the Military hospital of Avicenna in Marrakech and to report the epidemiological profile of malignant hemopathies diagnosed in our Laboratory.

\section{Material and Methods}

The retrospective study included 70 cases of malignant hemopathies, collected in the Hematology Laboratory of the Military hospital of Avicenna in Marrakech, over a period of two years, from January 2018 to December 2019. We included all requests for BM smears received in our Laboratory whose cytological aspect was in favor of malignant hemopathies. We excluded all cases of malignant hemopathies diagnosed outside our study period, BM smears not accompanied by a PB counts and smear, non hematological disorders and BM smear controls for patients already diagnosed. We collected demographic, clinical, radiological and hematological data. The PB count and smear allow quantitative and qualitative analysis of the elements of the blood and was performed using the Sysmex XT-4000I analyzer from blood samples collected by venipuncture on EDTA (ethylenediaminetetraacetic acid) tubes. The myelogram was performed by an operator that is aware of the clinical indications, the need for adequate sedation and analgesia, and of safety issues with regard to thrombocytopenia or coagulopathic risks. Informed consent was obtained from all patients. The anatomic site for myelogram was sternal for all patients except for one who had a posterior iliac crest aspirate. PB and marrow smears were stained with MGG (May-Grünwald-Giemsa). The BM smear preparation were first viewed under low power magnification $(* 10)$ to determine the number and cellularity of particles, the number of megakaryocytes, and to scan for clumps of abnormal cells. Areas of well-spread marrow cells in the cellular trails of the BM smear behind the particles were selected for assessment at higher magnification (i.e.*20,*40, *100) for morphological assessment of cells, including cytological detail. A BM nucleated differential cell count (NDC) was performed to assess haemopoietic activity and to compare the proportions of the different cell lineages with known reference ranges, and also to quantify abnormal cells, if present. In some cases, cytochemical stains were used for relevant analysis of myelogram such as: Myeloperoxidase and PERLS staining. The diagnosis of the various malignant hemopathies was made according to the classification criteria of the World Health Organization (WHO) 2008-2016.

\section{Results}

\subsection{Epidemiological Profile}

Out of 420 myelograms received in the Hematology Laboratory of the military hospital in Marrakech, 70 cases (17\%) of malignant hemopathies were collected. Benign hemopathies accounted for 120 cases $(29 \%)$. The reactional marrow was collected in 60 cases $(14 \%)$. Unsuccessful marrow and inconclusive marrow were found in 60 (14\%) and 110 cases $(26 \%)$ respectively (Figure 1$)$.

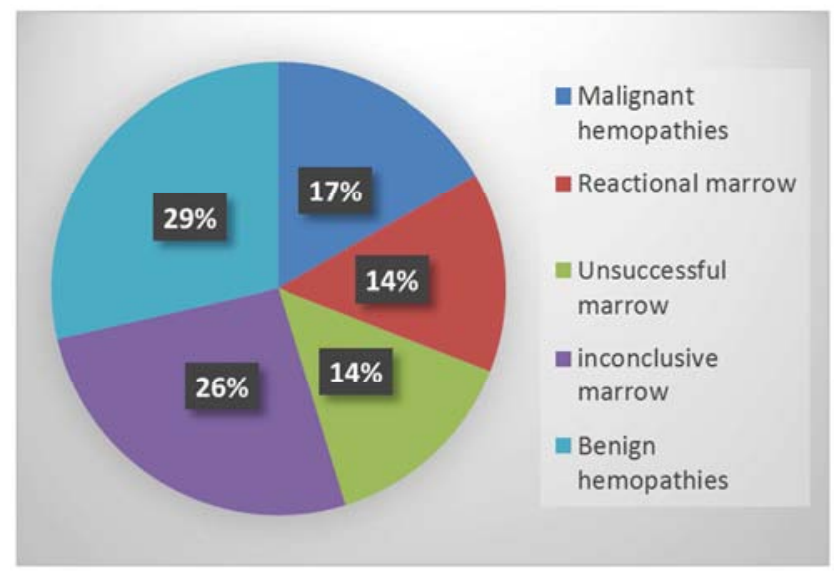

Figure 1. Distribution of myelogram results.

We objectified that all age ranges were affected with an average of 56 years with extremes ranging from 02 to 90 years. The predominant age range was 61 to 70 years old (Figure 2). The male gender was predominant $(64 \%)$ with a sex-ratio $(\mathrm{M} / \mathrm{F})$ at 1,8 .

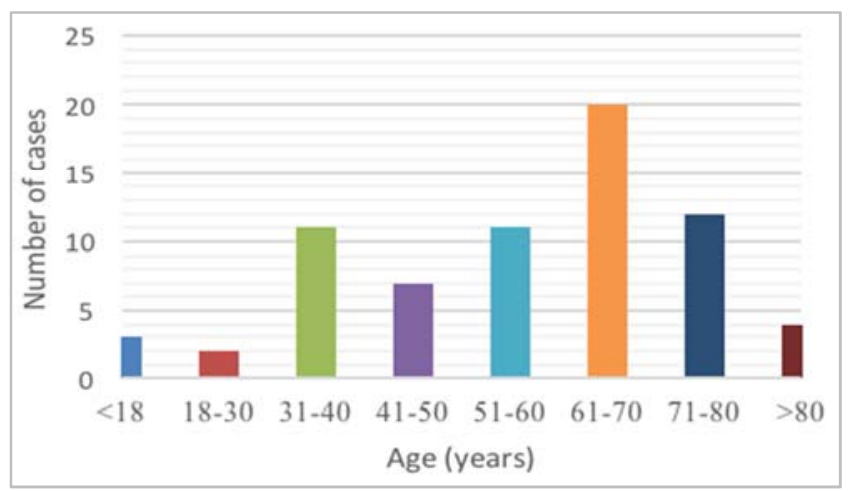

Figure 2. Distribution of malignant hemopathies cases according to age groups.

The majority of myelograms were performed in patients hospitalized in different departments, mainly in the clinical hematology and internal medicine departments. Seven requests were received for out-of-hospital patients. The following graph shows the different departments requesting myelograms in our study. (Figure 3). 


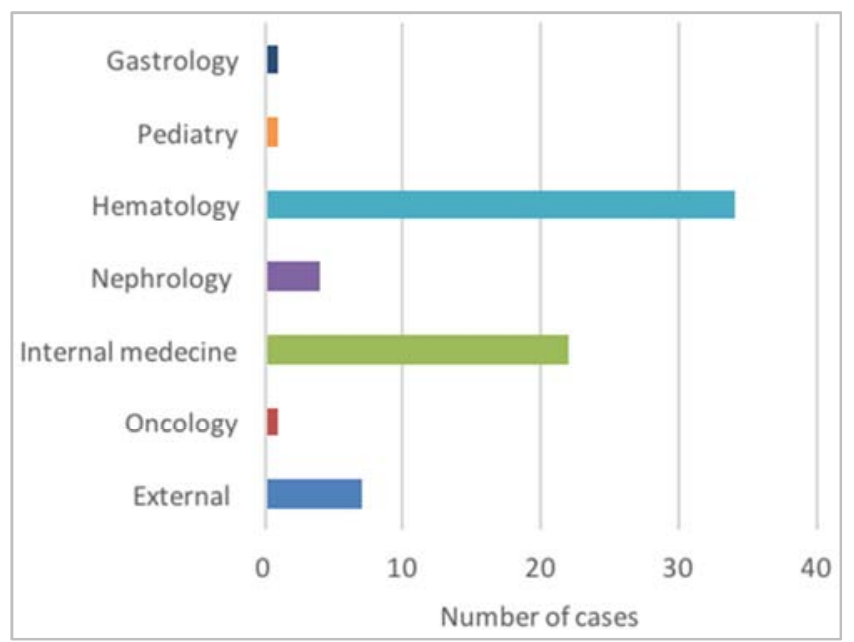

Figure 3. Distribution of malignant hemopathies cases according to the requesting services.

\subsection{Myelogram Indications}

\subsubsection{Clinical Indications}

In our study, anemic syndrome was predominant in $76 \%$ of cases, followed by tumor and bone syndrome in $21 \%$ and $20 \%$ of cases, respectively. The other indications were distributed in Figure 4.

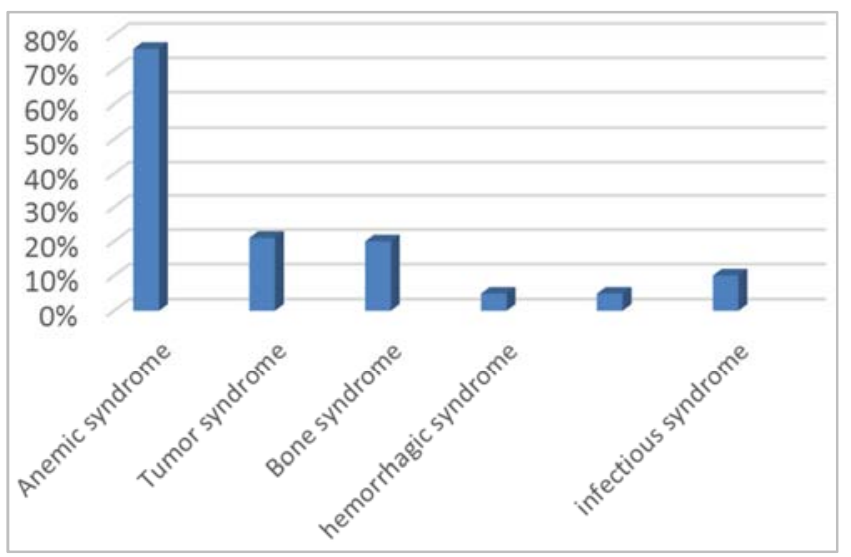

Figure 4. Distribution of clinical indications of myelogram.

\subsubsection{Biological Indications}

Blood counts were the first biological indication of the myelogram. In fact, all of our patients represented abnormalities in the PB count which required the practice of the myelogram. That was also performed during gammopathies in 13 patients, during an elevated sedimentation rate in 5 patients (Figure 5).

They were predominantly bicytopenia and hyperleukocytosis in 28 cases (40\%) and 23 cases (33\%), respectively. Isolated normochromic normocytic anemia (NNA) was described in 17 cases (24.3\%). Figure 6.

Microscopic examination of blood smears revealed abnormalities in $83 \%$ of cases and $17 \%$ of cases had inconclusive smears. The abnormalities encountered were predominantly the presence of myelemia and the presence of circulating blasts.

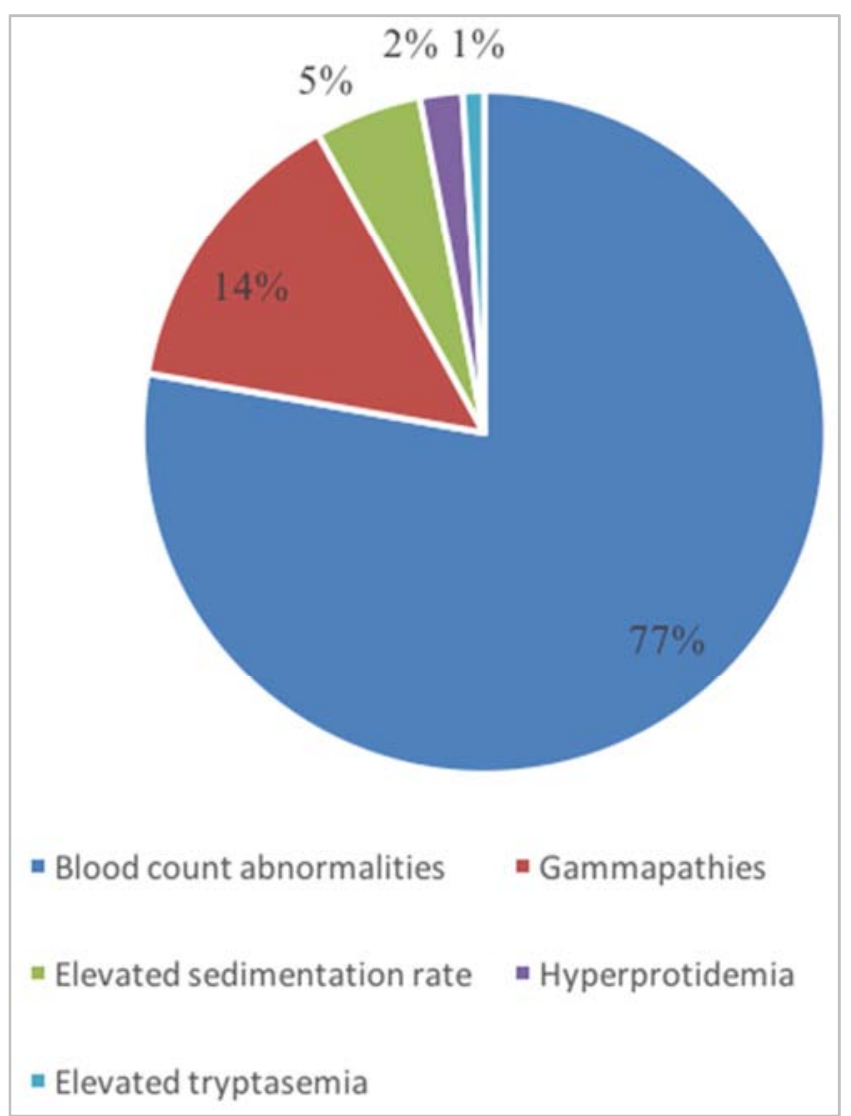

Figure 5. Distribution of biological indications of myelogram.

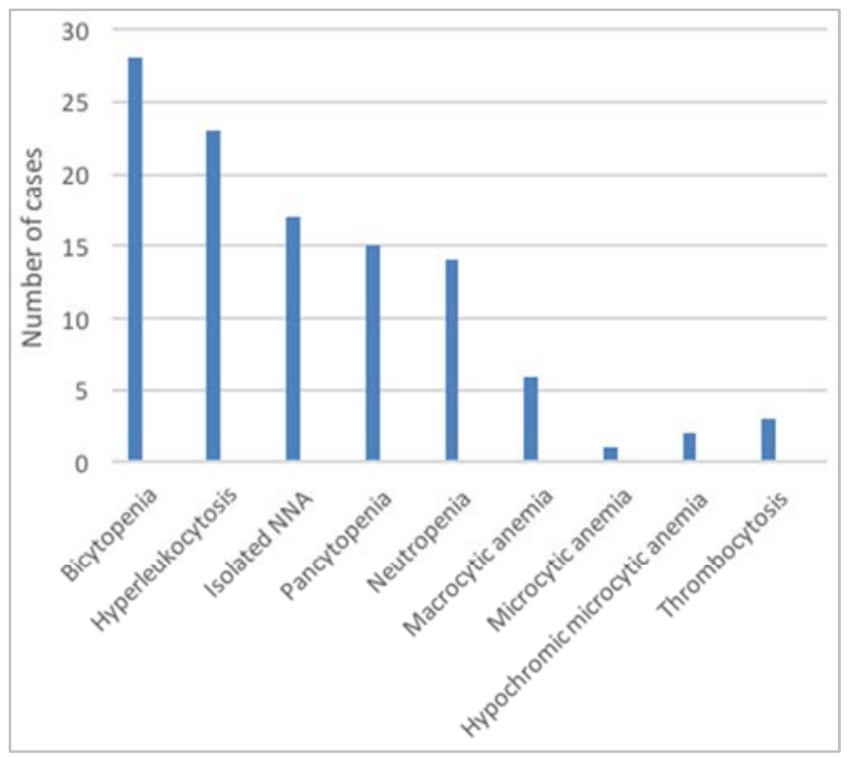

Figure 6. Blood count abnormalities in our population.

\subsection{BM Smear Abnormalities}

In our study, the majority of the marrows were of rich cellularity ( $42 \%$ of the cases). The moderately rich marrow was objectified in $30 \%$ of cases. (Figure 7 ). 


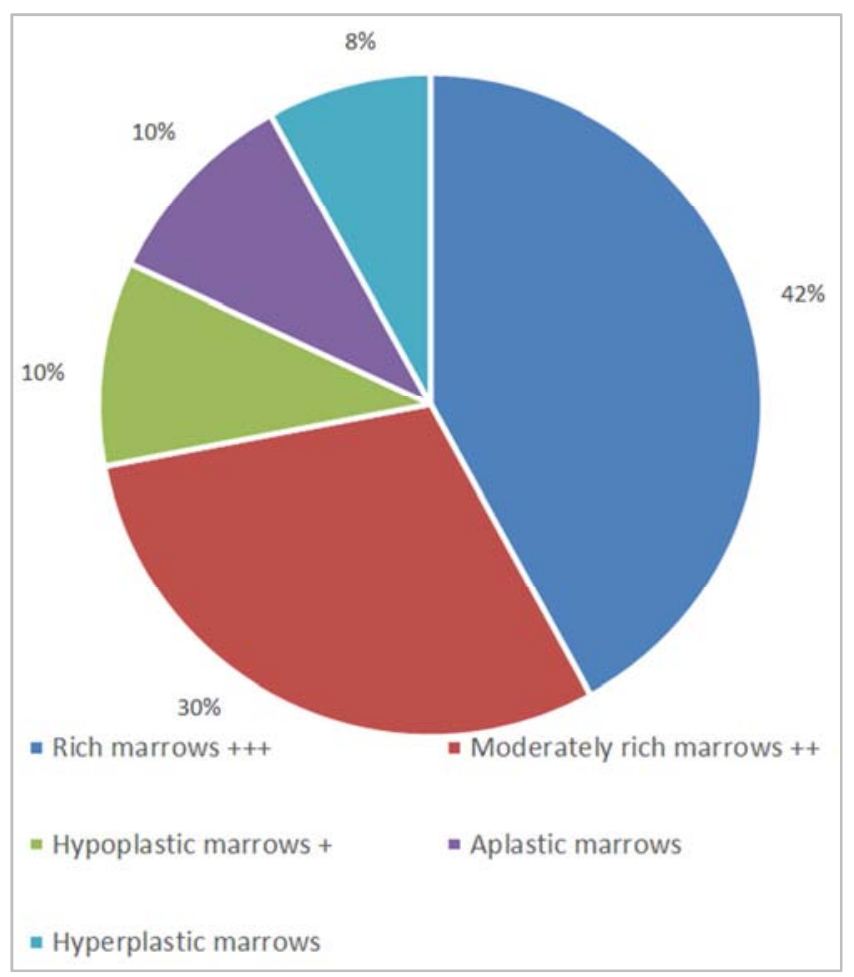

Figure 7. Distribution of myelograms according to cell richness.

Approximately $50 \%$ of our patients presented with bone marrow blastosis. Bone marrow plasmacytosis was described in 24 patients and signs of dysmyelopoiesis were present in 13 patients. Table 1.

Table 1. Abnormalities of the BM smear at high magnification.

\begin{tabular}{ll}
\hline BM smear abnormalities & Number of cases \\
\hline Blastosis & 34 \\
Plasmacytosis & 24 \\
Dysmyelopoiesis & 13 \\
Mast cells & 2 \\
Atypical lymphoid cells & 1 \\
Auer's body & 7 \\
\hline
\end{tabular}

\subsection{Malignant Hemopathies}

In our study, we had 70 cases of malignant hemopathies. Acute leukemias (AL) were in first place with 24 cases (35\%), followed by multiple myelomas (MM) with 23 cases (33\%), then myelodysplastic syndromes (MDS) with 12 cases (17\%) and Chronic myeloid leukemia (CML) was described in 6 cases $(9 \%)$. Medullary mastocytosis was found in 2 cases (3\%). Lastly, lymphoma, plasmocytic leukemia (PL) and chronic myelomonocytic leukemia (CMML) were present in one case for each entity. (Figure 8).

We collected 24 cases of acute leukemia (AL), or $35 \%$ of all malignant hemopathies. The mean age of the patients was 53.5 years. Male predominance was marked with a sex ratio of 1.4. Acute myeloblastic leukemia (AML) was predominant with 19 cases ( $79 \%$ of acute leukemias). Myeloperoxidase staining was positive in 13 patients. The distribution according to cytological type revealed a predominance of the type 2 AML cytological type in $48 \%$ of cases (Figure 9). Five cases of
Acute lymphoblastic leukemia (ALL) were diagnosed.

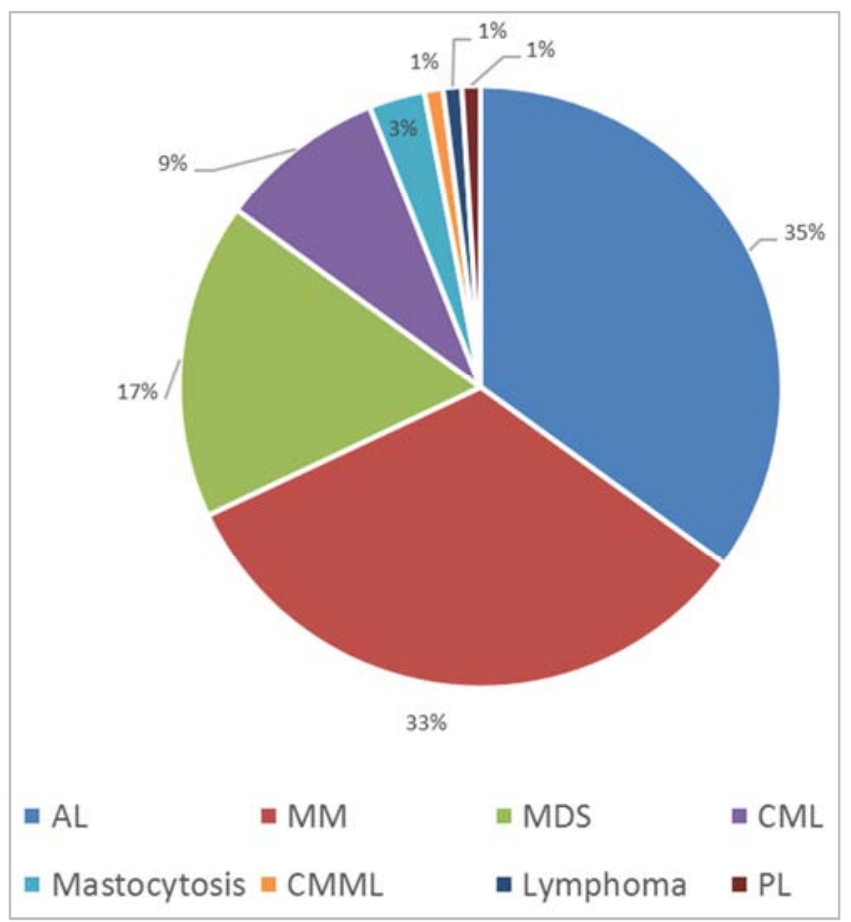

Figure 8. Different malignant hemopathies diagnosed in our study.

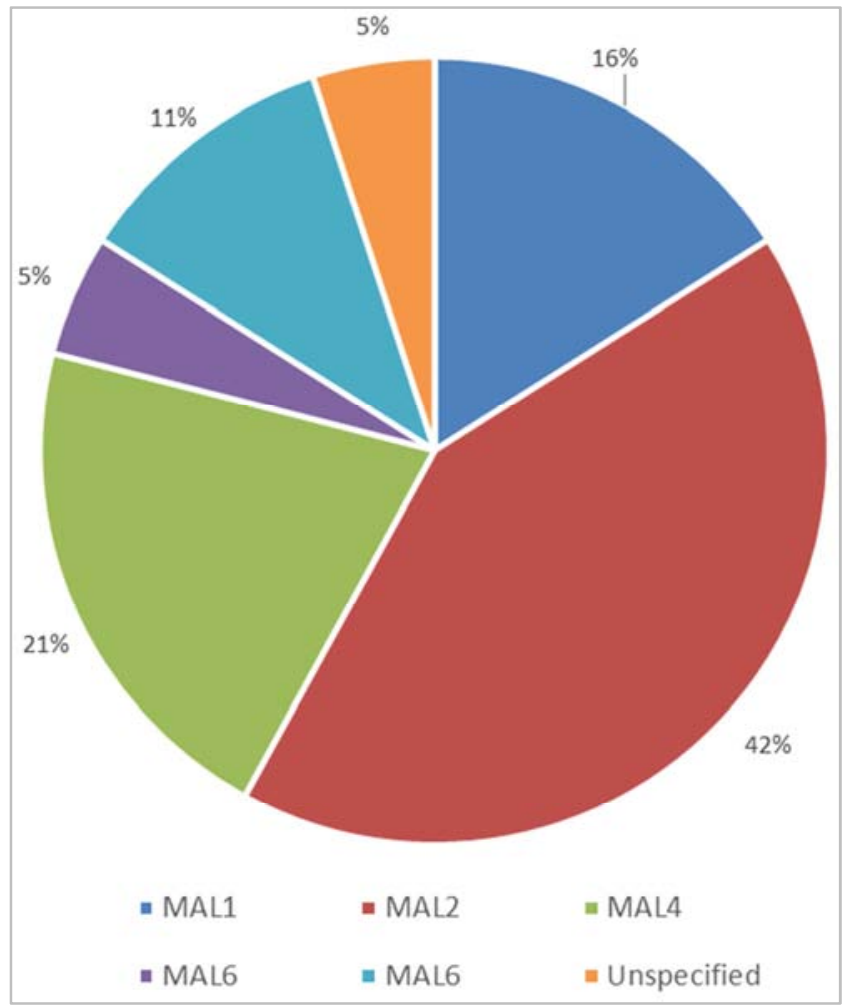

Figure 9. Distribution of AML according to cytological type.

\section{Discussion}

The myelogram is not a systematic examination, and it requires a technical platform and precise indications. In our laboratory and in the laboratory of the main hospital in Dakar 
[11], the myelogram is the second most requested examination after the PB count and smear. Over the period of our study, we collected 420 myelograms (210 per year). In Ivory Cost, the rate of this examination at the biology laboratory of the University Hospital of Treichville was 275 per year [12], which was close to our results and lower compared to that found in the hematology laboratory of the Ibn Sina Hospital Center (CHIS) in Rabat in 2016 (1100 myelograms / year) [13]. This is explained by the renovations carried out in 2010 as part of the centralization policy of the CHIS laboratories, becoming the Central Hematology Laboratory of CHIS Rabat.

Among the 420 myelograms received in our laboratory, 14\% were unsuccessful. They represented $10,6 \%$ and $28 \%$ respectivly in In Ivory Cost and in Rabat [12, 13]. In fact, it is not uncommon for the bone marrow aspirate sample to be diluted with blood. In this case, the cell count is not representative and the commentary on the myelogram should indicate that the sample was not contributing and suggest to redo the sample.

In our study, 70 cases of malignant hemopathies were collected with an annual rate of 35 cases / year. That was approaching the results of other studies that found annual rates at $33,41,45,51$ cases / year [12, 14, 15, 16]. Our results remain average compared to those of university hospital centers of Marrakech and Fez [17, 18].

In our series, the predominant age range was 61-70 years old. That was comparable to series made in Algeria [16] and in Lower Normandy in France [19]. In Cameroon [15] and at University hospital of Fez [17], the predominant age range was between 50 and 59 years old, which was close to our results. The average age of our patients was 56 years, while in Cameroon [15], Ivory Coast [12], the average age was respectively 44 years and 36 years. This is explained by the low percentage of the pediatric population in our series, which was less than 5\%. In Ivory Cost, children represented 14\% of all cases [12]. A male predominance was observed in our study and that was comparable to many other studies $[14,15$, $16,17,18]$. This could be explained by the fact that men are more exposed than women to environmental factors through their professional activities.

The majority of requests for myelogram came from the clinical hematology and internal medicine departments. Pediatric requests only represented $1.4 \%$ of cases. While in Ivory Cost, requests received from the pediatric service represented $14 \%$ of cases [12]. In our context, the majority of pediatric myelograms are studied at the University Hospital of Marrakech.
Clinically, the most common indications in order of frequency were: anemic syndrome, tumor syndrome, bone syndrome, infectious syndrome, AEG and hemorrhagic syndrome. In a series that analyzed the epidemiology of malignant hemopathies in hospitals in Cameroon [15], anemic syndrome and tumor syndrome represented the first clinical indications of the myelogram. Biologically, PB abnormalities were the first biological indication of myelogram in our series. PB count abnormalities were predominantly bicytopenia in $40 \%$ of cases, leukocytosis in 33\%. The PB smear abnormalities were predominated by the presence of blasts and the presence of myelemia. In Cameroon [15], abnormalities of the PB were also the first indication of myelogram which were predominantly NNA in $73.7 \%$ of patients, hyperleukocytosis in $57.3 \%$ and thrombocytopenia in $39.2 \%$ of cases.

In our study, Acute leukemias were the most frequent. Which was comparable to the series in Fez [17] and in Algeria [16]. They were in third place in the series in Ivory Cost [5]. In Cameroon, AL were in 4th place [15]. Multiple myeloma were ranked 2nd in our study, which was comparable to the results of Fez [17]. In France, the study showed that MM were ranked 3rd [19]. MDS were ranked 3rd in our series (17\%), which is close to the results found in Lower Normandy where MDS were ranked 4th (12.8\%) [19]. CML came in 4th position in $9 \%$ of malignant hemopathies, thus in agreement with the results of the series carried out in Fez [17] where they were in 4th place with a higher percentage. In the Algerian series [16], the CML were in 3rd position. In Cameroon, CML were ranked 2nd after AL [15]. In our series, lymphoma came last, unlike several series studied in Ivory Cost [12], Cameroon [15], France [19] and Algeria [16] in which lymphomas came first. This is due to the fact that our study was carried out in a biological hematology department, whose diagnostic tools do not include the histological study. We have found a case of plasma cell leukemia (PL) and a case of CMML. Similar results were found in the Fez study [17]. In our series, we have not collected any cases of Chronic lymphocytic leukemia (CLL). This is due to the fact that our series was limited to malignant hemopathies diagnosed by the myelogram, and that in our laboratory the diagnosis of CLL is made mainly by the blood count supplemented by immunophenotyping. In Ivory Cost [12] and France [19] CLLs ranked second after MDS in Ivory Cost and after lymphomas in France. A series in Cameroon [15] had objectified the CLL in 3rd position. In Algeria [16] and Fez [17], CLL were ranked in 4 th position. (Table 2).

Table 2. Frequency of malignant hemopathies in different studies.

\begin{tabular}{|c|c|c|c|c|c|c|c|c|}
\hline & AL & MM & CML & Lymphomas & MDS & CLL & PL & CMML \\
\hline Fez [17] & $25,4 \%$ & $22,2 \%$ & $21,7 \%$ & $4,6 \%$ & $6,8 \%$ & $14,2 \%$ & $0,5 \%$ & $0,5 \%$ \\
\hline Ivory Cost [12] & $12,5 \%$ & $10,7 \%$ & $7,54 \%$ & $60 \%$ & - & $9,5 \%$ & - & - \\
\hline Cameroon [15] & $16,1 \%$ & $11,2 \%$ & $21,4 \%$ & $31,1 \%$ & - & $12,6 \%$ & - & - \\
\hline France [19] & $9,6 \%$ & $13,7 \%$ & $2,3 \%$ & $31,1 \%$ & 12,8 & $16,7 \%$ & - & - \\
\hline Algeria [16] & $21,8 \%$ & $6 \%$ & $10 \%$ & $42 \%$ & $2,5 \%$ & $8,5 \%$ & - & - \\
\hline Our study & $35 \%$ & $33 \%$ & $9 \%$ & $1 \%$ & $17 \%$ & - & $1 \%$ & $1 \%$ \\
\hline
\end{tabular}

In our study, $\mathrm{AL}$ constituted $35 \%$ of all malignant hemopathies with predominance of AML (AML $=79 \%$ and
$\mathrm{ALL}=21 \%$ ). This was comparable to the results of University hospital of Marrakech [18] and those of Fez [17]. In series 
carried out in Rabat [6], AL were represented in higher percentages ( $62 \%$ of malignant hemopathies: $\mathrm{ALL}=58 \%$ and $\mathrm{AML}=42 \%$ ). The frequency of AL was lower in France [19], Ivory Coast [12] and Cameroon [15] which had identified AL in $9.6 \%, 12.5 \%$ and $16.1 \%$ respectively.

The cytological study showed a predominance of type 2 AML, this was consistent with studies in Marrakech [18], Rabat [13], France [19] and Tunisia [20]. The type 4 AML came in 2 nd position in our series, as well as the one made in Rabat [13] and in Marrakech [18]. In France [19] and Tunisia [20], AML4 were ranked 3rd. In our study, the AML5 were in 3rd place, thus approaching the results found in Tunisia [20] and Rabat [13] where they were in 4th place, The AML6 came in last position in our series.

We diagnosed $21 \%$ of ALL cases of all AL. Our results, as well as those of the French series [19] were significantly lower than the results found in Ivory Cost [12], Tunisia [20] and in Marrakech [18]. This is due to the fact that ALL mainly affects children, and that in our series, children only represented $4.28 \%$ of cases.

The practice of myelogram remains a mainstay for the workup of hematologic malignancies and their definitive diagnosis. The quick nature of the procedure, the potential for avoidance of sedation or general anesthesia, and the ability to perform the procedure on an outpatient basis facilitate an efficient path towards diagnosis and treatment as well as a non-traumatic experience for the patient [21].

\section{Conclusion}

Bone marrow examination is an important step to arrive at the confirmatory diagnosis of many hematological disorders. Its contribution in diagnostic of malignant hemopathies is based on its good interpretation which is directly linked to the rigor of its realization and to the collaboration between the clinician and the biologist. The incidence of malignant hemopathies has increased significantly in recent years around the world. This encourages us to better understand the physiopathological mechanisms of each entity to develop prevention, screening and treatment protocols adapted to our Moroccan context.

\section{References}

[1] Thiam D, Diop TM, Tallarmin F, Toure AO, Diakhate L. (1996) Epidemiology and therapy of malignant hemopathies in Senegal. Hematol Cell Ther; 38: 187-91.

[2] Ouédraogo SM, Hien F, Bazié W, Millogo A, Drabo YJ. (2011) Place des hémopathies malignes en service de Médecine interne du CHU SouroSanou (Burkina Faso). [Place of Hematologic malignancies in internal medicine UHC Souro Sanou (Burkina Faso)] Mali Médical; XXVI: 17-21.

[3] Mufuta NJP, Mbayo K, Kayembe NZ, Gini EK, Mbuyi M. (2013) Cytologie des hémopathies malignes dans deux formations médi- cales de Kinshasa. [Cytological profil of hematological malignancies in two medical institutions in Kinshasa]. Ann AfrMed; 6.
[4] Elloumi M, Hafsia R, Omri EL, et al. (2002) Caractéristiques épidémiologiques, cliniques et cytohématologiques des leucémies aigués lymphoblastiques de l'adulte en Tunisie. [Epidemiological, clinical and cytohematological characteristics of acute lymphoblastic leukemia in adults in Tunisia ]. Tunis Médical; 80: 199-202.

[5] Sebahoun G, Sainty D, Horschowski N. (1991) Ponction médullaire et biopsie médullaire. [Medullary puncture and bone marrow biopsy]. Editions techniques. Encycl. Méd. Chir. (Paris, France), Hématologie 13000, A30, 7p.

[6] Téa D, Yao T, Abissey A, Anoh J, Rain JD. Panorama des hémopathies diagnostiquées au laboratoire central du CHU de Treichville bilan de 10 années d'activité.[Overview of hemopathies diagnosed at the central laboratory of the University Hospital of Treichville assessment of 10 years of activity]. Médecine d'Afrique Noire: 39-43.

[7] Goldberg $\mathrm{C}$ et al. Bone marrow aspiration and biopsy transfusion. http://emedicine.medscape.com/article/207575, consulté le 24 oct. 2017.

[8] Riley RS, Hogan TF, Pavot DR, et al. A pathologist's perspective on bone marrow aspiration and biopsy: (2004) I. Performing a bone marrow examination. J Clin Lab Anal; 18 (2): 70-90.

[9] Lee S-H, Erber WN, Porwit A, Tomonaga M, Peterson LC. (2008) International Council for Standardization In Hematology. ICSH guidelines for the standardization of bone marrow specimens and reports. Int J Lab Hematol; 30 (5): 349 64.

[10] McFadden S., Briggs C., Davis B., Jou J. \& Machin S. (2008) The reformed International Council for Standardization in Hematology (ICSH). International Journal Journal of Laboratory Hematology 30, 89- 90.

[11] HUGARD L., ABDOU SOULEY A., NDOYE B., SACCHARIN C. (1995) Affections hématologiques et myélogramme. Bilan de 5 ans à l'hôpital principal de Dakar (Sénégal). [ Blood disorders and myelogram. 5-year review at the main hospital in Dakar (Senegal) ]. Méd. Afr. Noire- 42, (11): 605-611.

[12] Ouattara S, Danho B, Kone M, Tea D. (2000) La pratique du myélogramme au chu de Treichville: bilan de 19 années d'activité. [The practice of the myelogram at the University hospital of Treichville: review of 19 years of activity] Médecine d'Afrique Noire; 47, 5.

[13] El Hamdaoui O. (2018) Apport du myélogramme dans le diagnostic des hémopathies: expérience du laboratoire central d'hématologie de l'Hôpital IBN SINA RABAT. [Contribution of the myelogram in the diagnosis of hemopathies: experience of the central hematology laboratory of the IBN SINA RABAT Hospital]. Thèse de médecine, Rabat; N 22.

[14] Diallo D. A, Cissoko L. S, Cissoko Y, Baby M et al.(2005) Epidémiologie actuelle des hémopathies malignes dans les services d'hématologie oncologie médicale et de médecine interne de l'hôpital du Point G, Bamako, Mali. [Updated epidemiology of haematological malignancies in the haematology \& oncology and the internal medicine wards of the hospital of Point G, Bamako, Mali]. Mali Médical; 4-8.

[15] Moueleu Ngalagou P. T, Ngouadjeu Dongho Tsakeu E, Ngo Sack F, Eboumbou Moukoko E. C et al. (2018) Epidemiology of malignant hemopathies recorded in hospitals in Cameroon. Medecine et santé Tropicales Janvier 2018; 28, 1: 61-66. 
[16] Bachir Bouiadjra S, Moulessehoul S, Sebaa A, Snouci A et al. (2009) Apport de la cytogénétique moléculaire à l'étude des hémopathies malignes chez des patients hospitalisés à l'hôpital de Sidi-Bel-Abbès (Algérie). [Contribution of the molecular cytogenetics being studied of the hematological malignacies among patients hospitalized in hospital of Sidi-Bel-Abbès]. African Journal of Cancer; 1, 4: 188-192.

[17] KHALKI H. (2017) Profil épidémiologique et diagnostique des hémopathies malignes: expérience du laboratoire d'hématologie du CHU Hassan II de Fès. [Epidemiological and diagnostic profile of hematologic malignancies: experience of the hematology laboratory of the university hospital Hassan II in Fez]. Thèse de médecine, Fès.

[18] RHAFEL A. (2014) Bilan d'activité de service d'hématologie CHU MARRAKECH (2009-2013). [The University Hospital of MARRAKECH hematology department activity report (2009-2013)]. Thèse de médecine, Marrakech; N 47.
[19] Troussard X, Duchenet V, Cornet E, Mouchel D et al. (2009) Épidémiologie des hémopathies malignes en Basse-Normandie. [Epidemiology of malignant hemopathies in Lower Normandy]. Revue d'Épidémiologie et de Santé Publique; 57, 3: 151-158.

[20] Jmili N. B, SENDI S. H, KHELIF A, SAAD A. (2010) Leucémies aiguës myéloïdes en Tunisie: caractéristiques épidémiologiques et cliniques et classification OMS.[Acute myeloid leukemia in Tunisia: epidemiological and clinical characteristics and WHO classification]. Journal Africain du Cancer; 2, 1: 25-32.

[21] Rindy LJ, Chambers AR. Bone Marrow Aspiration And Biopsy. 2021 Jul 25. In: StatPearls [Internet]. Treasure Island (FL): StatPearls Publishing; 2021 Jan-. PMID: 32644658. 